Check for updates

Cite this: RSC Adv., 2019, 9, 4942

Received 27th November 2018 Accepted 26th January 2019

DOI: $10.1039 / c 8 \mathrm{ra09764j}$

rsc.li/rsc-advances

\section{Designing photolabile ruthenium polypyridyl crosslinkers for hydrogel formation and multiplexed, visible-light degradation $\uparrow$}

\author{
Teresa L. Rapp, ${ }^{a}$ Yanfei Wang, ${ }^{b}$ Maegan A. Delessio, ${ }^{a}$ Michael R. Gau ${ }^{a}$ \\ and Ivan J. Dmochowski iD *a
}

\begin{abstract}
Photoresponsive materials afford spatiotemporal control over desirable physical, chemical and biological properties. For advanced applications, there is need for molecular phototriggers that are readily incorporated within larger structures, and spatially-sequentially addressable with different wavelengths of visible light, enabling multiplexing. Here we describe spectrally tunable $\left(\lambda_{\max }=420-530 \mathrm{~nm}\right)$ ruthenium polypyridyl complexes functionalized with two photolabile nitrile ligands that present terminal alkynes for subsequent crosslinking reactions, including hydrogel formation. Two Ru crosslinkers were incorporated within a PEG-hydrogel matrix, and sequentially degraded by irradiation with $592 \mathrm{~nm}$ and $410 \mathrm{~nm}$ light.
\end{abstract}

\section{Introduction}

Photoresponsive molecules and materials are transforming multiple areas of research, from drug delivery, ${ }^{1-6}$ to materials engineering, ${ }^{7-15}$ and biology. ${ }^{16-26}$ Many natural biological processes are not photoresponsive, making light a versatile trigger for controlling complex biological systems. ${ }^{27}$ The incorporation of photoactive moieties within biomolecules, ${ }^{24}$ smallmolecule drugs ${ }^{28}$ and materials ${ }^{7}$ provides a method for modulating their activity. Likewise, photoactive moieties incorporated within soft materials, e.g., polymers, hydrogels, and elastomers, enable spatiotemporally precise, light-guided modulation of structure-function properties. Photoresponsive hydrogels in particular have long been used as platforms for cell growth and delivery, for small and large molecule drug delivery, ${ }^{29,30}$ and for basic materials applications. ${ }^{31}$ To expand methods for tuning soft material properties, e.g., shape and viscosity, we developed differentially photoresponsive ruthenium moieties suitable for hydrogel formation and subsequent multiplexed ligand dissociation.

A drawback to most current photoresponsive molecules is the high-energy light required for bond dissociation. Common photoresponsive organic chromophores, e.g., $O$ nitrobenzyl, ${ }^{32}$ azobenzene, ${ }^{14}$ and coumarin, ${ }^{30,33}$ respond to near-UV and blue light, which barely penetrates most

\footnotetext{
${ }^{a}$ Department of Chemistry, University of Pennsylvania, $231 \mathrm{~S} 34^{\text {th }}$ St., Philadelphia, PA, USA. E-mail: ivandmo@sas.upenn.edu

${ }^{b}$ Department of Anesthesiology, Division of Critical Care Medicine Boston Children's Hospital, Harvard Medical School, 300 Longwood Avenue, Boston, MA, USA

$\dagger$ Electronic supplementary information (ESI) available. CCDC 1875400-1875402. For ESI and crystallographic data in CIF or other electronic format see DOI: 10.1039/c8ra09764j
}

biomaterials or live tissue. Attempts to red-shift the activation wavelength have focused on multiphoton excitation, ${ }^{\mathbf{1 0 , 3 4 - 3 7}}$ coupling with upconverting nanoparticles ${ }^{\mathbf{3 6 , 3 8}}$ or chemically modified chromophores. ${ }^{39}$ Some limiting factors include the small activation volume of multiphoton processes, the potential toxicity of embedded nanoparticles, low quantum yields (leading to sample heating and photodamage during repeated illumination), and synthetic complexity.

To address these challenges, we have worked to develop inorganic photoactive molecules that absorb orange-red light, which has greater penetration depth and is less prone to photodamage in clinical applications. ${ }^{37}$ Our laboratory has expanded the use of photolabile ruthenium crosslinkers for applications in biology and soft materials. The first Ru-based crosslinker, $\left.\left(\mathrm{Ru}(\text { bipyridine })_{2} \text { (3-ethynylpyridine }\right)_{2}\right) \quad$ (Ru-BEP), presented two alkynes for the circularization of antisense bisazide-modified oligonucleotides for light-activated gene knockdown in zebrafish embryos. ${ }^{21}$ A related compound, $\mathrm{Ru}$ (bipyridine) ${ }_{2}$ (3-pyridinaldehyde) ${ }_{2}$ (RuAldehyde), provided a light-responsive crosslinker for hydrogel formation, siteselective degradation and protein release. ${ }^{29}$

These $\mathrm{Ru}$ polypyridyl complexes share the unique ability to exchange a monodentate pyridine ligand with solvent upon irradiation with visible light. Single-site photo-substitution has been observed for other $\left[\mathrm{Ru}(\text { polypyridyl })_{2} \mathrm{X}_{2}\right]^{2+}$ complexes, where $\mathrm{X}=$ pyridine- $^{\mathbf{2 , 4 0 - 4 2}}$ or sulphur-containing ${ }^{\mathbf{4 3}}$ ligands. Alternatively, two nitrile ligands $\mathrm{s}^{\mathbf{4 4 , 4 5}}$ can both undergo rapid photo-substitution (Fig. 1A). Excitation into the singlet metal-toligand charge transfer $\left({ }^{1} \mathrm{MLCT}\right)$ band initiates intersystem crossing to a low-lying triplet state (Fig. 1B). In most photoresponsive Ru-polypyridyl complexes this triplet state is primarily ${ }^{3}$ MLCT in character, with another triplet metal- 
A)

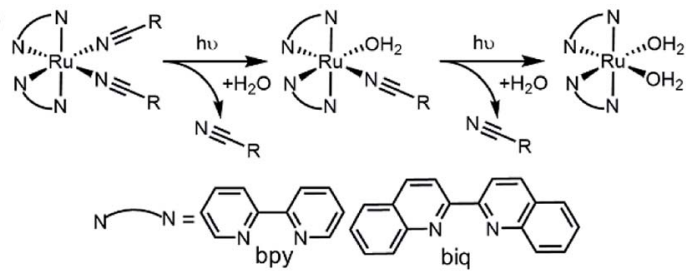

B)

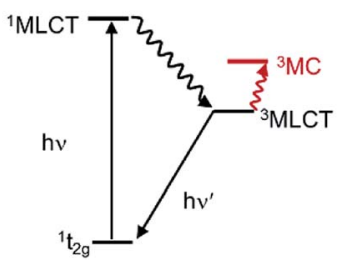

Fig. 1 Photoinitiated ligand exchange in ruthenium polypyridyl complexes. (A) Photolysis observed for Ru(॥)-nitrile complexes is a two-step process in which both ligands are exchanged with coordinating solvent. (B) Jablonski diagram showing excited states responsible for ligand.

centred $\left({ }^{3} \mathrm{MC}\right)$ state close enough in energy to be thermally populated.

In the current study, our goal was to red-shift the absorption of $\mathrm{Ru}$ crosslinkers for multiplexing applications, while incorporating two photolabile nitrile-based ligands for maximum photodissociation within a hydrogel. ${ }^{46}$ Inspired by previous work from Turro and coworkers, we designed a series of $\mathrm{Ru}$ crosslinkers incorporating biquinoline ligands that red-shift the maximum absorption wavelength, $\lambda_{\max }{ }^{46}$ The biquinoline also increased the steric strain around the Ru center, increasing the quantum yield of photorelease, $\Phi_{\mathrm{pr}}{ }^{47}$ This technique has led to several applications of red-light-absorbing, photoresponsive materials incorporating polypyridyl ruthenium compounds. ${ }^{48,49}$ Here, we present the first examples of red-shifted $\mathrm{Ru}$ compounds that incorporate crosslinking functionality and achieve hydrogel formation, while enabling wavelengthselective degradation with visible light.

We present a series of alkyne-bearing $\mathrm{Ru}(\mathrm{II})$ compounds with nitrile-based photolabile ligands (compounds 1-3, Fig. 2). Starting from $\mathrm{Ru}$ (bipyridine $)_{2}(5 \text {-hexynenitrile) })_{2}, \quad \lambda_{\max }$ was sequentially red-shifted by incorporating 1 or 2 biquinoline ligands (Fig. 2). A crystallographic analysis confirmed that 5hexynenitrile appropriately positions the pendant alkyne for subsequent reaction with an azide-modified branched polyethylene glycol (PEG) polymer (10 kDa) via copper(I)-catalyzed alkyne-azide cycloaddition (CuAAC).$^{50,51}$ The resulting hydrogels, formed with Ru crosslinkers 1 and 3, allowed spatially selective degradation via two different wavelengths of visible light (592 and $410 \mathrm{~nm}$ ).

\section{Results and discussion}

Compound 1 was synthesized from commercially available Rubpy ${ }_{2} \mathrm{Cl}_{2}$ and 5-hexynenitrile through the $\mathrm{Ru}(\mathrm{bpy})_{2}\left(\mathrm{H}_{2} \mathrm{O}\right)_{2}$ intermediate generated by the addition of $\mathrm{AgPF}_{6}$ to form $\mathrm{AgCl}$ precipitate. 1-3 were purified as the $\mathrm{PF}_{6}{ }^{-}$salt via silica column flash chromatography $(1: 4$ acetonitrile : methylene chloride

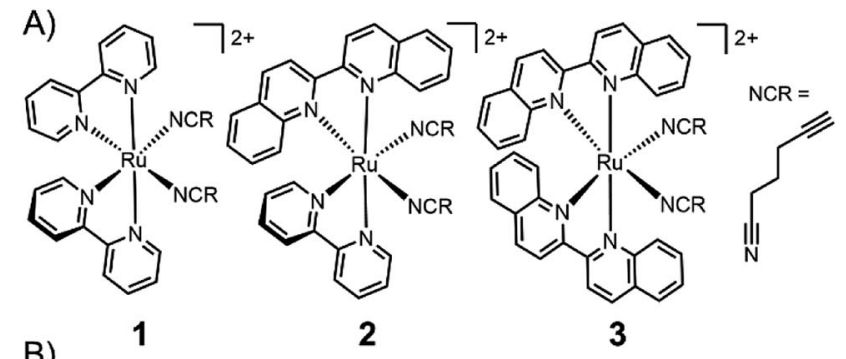

B)

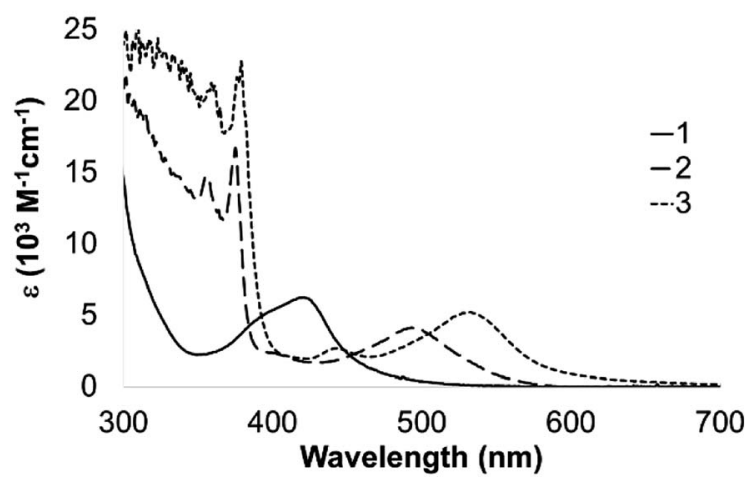

Fig. 2 Ru crosslinkers with two photolabile nitrile ligands. (A) Three compounds synthesized in this study. (B) Molar absorption spectra for $1-3$.

mobile phase), and isolated as the nitrate salt using an Amberlite@ IRA-410 column in good yield (54\%) (see ESI $\uparrow$ for synthetic details). The nitrate counterion gave $\mathrm{Ru}^{2+}$ polypyridyl complexes with excellent solubility and stability in water (Fig. S1†).

To generate $\mathrm{Ru}(\mathrm{bpy})(\mathrm{biq}) \mathrm{Cl}_{2}$ for 2 we found it necessary to use the benzene ruthenium dimer [(benzene) $\left.\mathrm{RuCl}_{2}\right]_{2}$ to ensure conversion to the mixed ligand product. Bipyridine was coordinated first to generate $\mathrm{Ru}(\mathrm{bpy}) \mathrm{Cl}_{4}{ }^{2-}$, which was purified by filtration, followed by addition of biquinoline and heating to give $\mathrm{Ru}(\mathrm{bpy})(\mathrm{biq}) \mathrm{Cl}_{2}$, which was purified by precipitation into diethyl ether, in $55 \%$ yield. Subsequent coordination of two 5hexynenitrile ligands gave 2 in a final overall yield of $13.5 \%$. Compound 3 was synthesized starting with $\mathrm{RuCl}_{3} ; 2.2$ equivalents of biquinoline were added with hydroquinone as the reducing agent and excess $\mathrm{LiCl}$ to generate the intermediate Rubiq $\mathrm{Cl}_{2}$, which was isolable by precipitation into ether in $33 \%$ yield. Coordination of 5-hexynenitrile proceeded by the same procedure as for $\mathbf{1}$ and 2, giving 3 as nitrate salt in overall $24 \%$ yield. All compounds were characterized by ${ }^{1} \mathrm{H}$ NMR spectroscopy, high-resolution ESI mass spectrometry, and UV-Vis absorption spectroscopy (see ESI†).

Ruthenium polypyridyl complexes exhibit strong absorbance in the visible region due to the low-lying metal-to-ligand charge transfer (MLCT) band. In this state, electrons are excited from the ground state orbital located primarily on the metal center to a low-lying excited orbital located on the polypyridyl ligand, at higher energy for bipyridine than biquinoline. ${ }^{46}$ Ligands with more extended pi bonding tend to lower the energy of the ${ }^{1}$ MLCT band, and red shift the absorbance.

The ${ }^{1}$ MLCT absorption maxima for 1,2 , and 3 were 419,491 , and $529 \mathrm{~nm}$, respectively ( $\varepsilon$ reported in Table 1). A shift of over 
Table 1 Absorptivities and quantum yields for 1-3

\begin{tabular}{lll}
\hline & $\varepsilon\left(\mathrm{M}^{-1} \mathrm{~cm}^{-1}\right)$ & $\Phi_{\mathrm{pr}}$ \\
\hline $\mathbf{1}$ & $6140 \pm 100$ & $0.16 \pm 0.02 @ 450 \mathrm{~nm}$ \\
2 & $1900 \pm 100$ & $0.19 \pm 0.005 @ 532 \mathrm{~nm}$ \\
3 & $7400 \pm 400$ & $0.07 \pm 0.01 @ 532 \mathrm{~nm}$
\end{tabular}

$70 \mathrm{~nm}$ was observed with the first substitution of a bipyridine for biquinoline ligand, from 1 to 2 (Fig. 2A), followed by a nearly $40 \mathrm{~nm}$ red-shift from 2 to 3 . This shows good agreement with previously published spectra for $\mathrm{Ru}(\text { phen })_{2}(\mathrm{MeCN})_{2}\left(\lambda_{\max }=420\right.$ $\mathrm{nm}), \mathrm{Ru}($ phen $)(\mathrm{biq})(\mathrm{MeCN})_{2}\left(\lambda_{\max }=497 \mathrm{~nm}\right)$, and $\mathrm{Ru}(\mathrm{biq})_{2}(-$ $\mathrm{MeCN}_{2}\left(\lambda_{\max }=535 \mathrm{~nm}\right){ }^{46}$

The photolysis of ruthenium polypyridyl compounds can be observed directly using UV-Vis spectroscopy. As the compound undergoes ligand exchange of a coordinated ligand for a solvent molecule, a significant red shift is observed in the MLCT band. Under continuous irradiation, compounds 1-3 sequentially exchanged both nitrile ligands (Fig. 3A, S2 $\dagger$ ). The UV-Vis photolysis curve for 3 is shown in Fig. 3B, where peaks at 560 and $590 \mathrm{~nm}$ indicated a stepwise process, with a monoaquated intermediate. The clear isosbestic points at 550 and $570 \mathrm{~nm}$ also indicated the stepwise transition from 3 to monoaquated $3^{\prime}$ to bisaquated $3^{\prime \prime}$, although the first transition point at $550 \mathrm{~nm}$ included early formation of $3^{\prime \prime}$ under continuous irradiation.

The loss of the second nitrile ligand in $\mathbf{3}$ was slower, occurring on the order of $40 \mathrm{~min}$ (Fig. 3B), compared to the first ligand exchange event, which was completed within 4 min of constant irradiation in the bulk sample. This trend was observed for $\mathbf{1}$ and 2 as well (Fig. S2 $\dagger$ ). The Ru MLCT band extends well beyond the $\lambda_{\max }$, which can be used to induce ligand exchange at longer wavelengths of light; irradiation at 600-700 $\mathrm{nm}$ (red incandescent light bulb, $5 \mathrm{~mW}$ ) was less efficient but led to complete photolysis of 3 in $4 \mathrm{~h}$ (Fig. S3†).

Photolysis data were fit to an equation derived from a pseudo-first order kinetics process, and the time constants were determined (Fig. S4 $\dagger$ ). The value of $\Phi_{\mathrm{pr}}$ was found for the

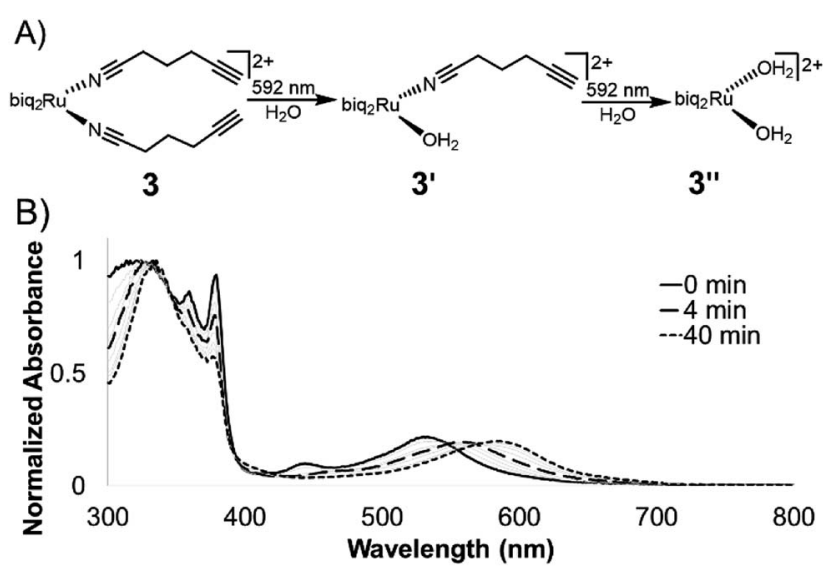

Fig. 3 Photolysis of 3 in water. (A) Compounds 1-3 undergo a stepwise ligand exchange of both nitrile ligands when irradiated in water. The second step takes much longer than the first. (B) Photolysis trace of 3 in water under irradiation from $592 \mathrm{~nm}$ LED $\left(25 \mathrm{~mW} \mathrm{~cm}{ }^{-2}\right)$.

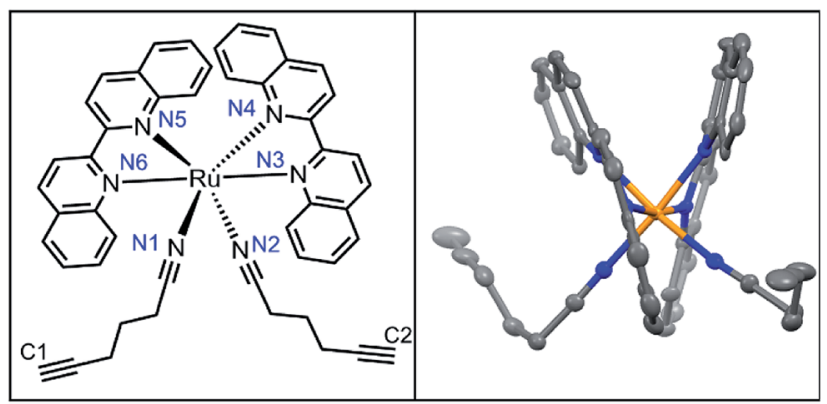

Fig. 4 Crystal structure of 3 .

first exchange event from the rate constant coupled with the laser power (Fig. S4 $\dagger$ ). As expected, $\Phi_{\mathrm{pr}}$ decreased roughly 2-fold as the MLCT band was shifted further to the red, from 0.16 (in 1) to 0.07 (in 3), Table $1 .^{52,53}$ Similarly, the efficiency of photolysis for $3\left(\varepsilon \times \Phi_{\mathrm{pr}}=520 \mathrm{M}^{-1} \mathrm{~cm}^{-1}\right)$ was lower than 1 at $980 \mathrm{M}^{-1} \mathrm{~cm}^{-1}$. Although these values were lower than other published ruthenium caging groups, with efficiencies that range from 2000 (ref. 46) to $4000 \mathrm{M}^{-1} \mathrm{~cm}^{-1}$, 29 they are significantly improved over other green-light-sensitive caging groups like BODIPY, with $\Phi_{\mathrm{pr}}$ on the order of $100 \mathrm{M}^{-1} \mathrm{~cm}^{-1} .{ }^{54,55}$

Diffraction-quality crystals of 3 as $\mathrm{PF}_{6}{ }^{-}$salt were grown via vapour diffusion from $3-5 \mathrm{mg}$ dissolved in acetonitrile/ methanol/THF ( $0.1 \mathrm{~mL}$ each) with diethyl ether, stored at $-20{ }^{\circ} \mathrm{C}$ for 2 weeks (Fig. 4). Bond lengths between $\mathrm{Ru}^{2+}$ and ligands were within expected ranges, with variations due to the steric strain in the system. The angle between the nitrile ligands is stretched significantly to $>95^{\circ}$ perhaps due to the strain caused by bulkier biq ligands coordinated to $\mathrm{Ru}^{2+}$. In the less crowded $\mathrm{Ru}(\mathrm{bpy})(\mathrm{biq})(5 \text {-hexynenitrile })_{2}$ compound, the nitrile$\mathrm{Ru}$-nitrile angle is $\sim 90^{\circ}$ (Fig. S5 $\dagger$ ). Crystal structure of 3 shows alkynes positioned $4.3 \AA$ and $4.9 \AA$ from biquinolines, angled such that they are accessible for cycloaddition with azide and copper catalyst (Table 2).

The conformational flexibility of the nitrile-alkyl ligands required synthesis and testing of several $\mathrm{Ru}$ compounds to identify competent crosslinkers. Initially, $\mathrm{Ru}$ compounds employing a shorter 4-pentynenitrile ligand were synthesized and found to be incapable of $\mathrm{Cu}(\mathrm{I})$-mediated PEG gelation (Fig. S6 $\dagger$ ). Incorporation of longer 5-hexynenitrile ligands led to functional $\mathrm{Ru}$ crosslinkers, but only after mild synthetic conditions for nitrile coordination were employed. Ru-(5-hexynenitrile) coordination performed at elevated temperatures and longer reaction times resulted in $\mathrm{Ru}$ compounds found to be incapable of $\mathrm{Cu}(\mathrm{I})$-mediated PEG gelation. X-ray crystal

Table 2 Select bond lengths, from X-ray crystal structure of 3

\begin{tabular}{lll}
\hline & Bond & $3(\AA)$ \\
\hline $\mathrm{Ru}-$ biq & $\mathrm{Ru}-\mathrm{N} 4$ & $2.084(6)$ \\
& $\mathrm{Ru}-\mathrm{N} 3$ & $2.093(6)$ \\
$\mathrm{Ru}-\mathrm{N} \equiv \mathrm{C}$ & $\mathrm{Ru}-\mathrm{N} 1$ & $2.025(6)$ \\
& $\mathrm{Ru}-\mathrm{N} 2$ & $2.024(6)$ \\
$\mathrm{C} \equiv \mathrm{C}$ to biq & $\mathrm{C} 1-\mathrm{biq}$ & 4.267 \\
& $\mathrm{C} 2-$ biq & 4.926
\end{tabular}


structure analysis of one such example shows alkyne positioned much closer to the biquinoline, only $3.7 \AA$ (Fig. S5†). The cisalkane conformation should disfavour $\mathrm{Cu}(\mathrm{I})$-mediated alkyneazide cycloaddition chemistry. $\mathrm{Ru}$ compounds 1-3 were synthesized using the mild conditions detailed in the Synthetic Procedure and confirmed to be excellent crosslinkers in gelation studies.

CuAACs have been widely used for materials design, with several studies showing the generation of hydrogel materials. Hyaluronic acid, ${ }^{\mathbf{5 6}, 57}$ polyethylene glycol (PEG), ${ }^{58}$ dextran, ${ }^{59}$ poly(vinyl) alcohol (PVA), ${ }^{60}$ along with several other polymers have been modified with azides and terminal alkynes to facilitate hydrogel formation. The need for a $\mathrm{Cu}(\mathrm{I})$ catalyst has limited some bio-applications as it can be toxic to cells, ${ }^{61}$ but can also provide spatiotemporal control. In one example Bowman and co-workers used a photocatalyst to reduce $\mathrm{Cu}(\mathrm{II})$ for the formation of a hydrogel with precise control. ${ }^{62}$ Copper can be dialysed away from preformed hydrogels, which is acceptable for many drug delivery platforms.

Compounds 1-3 were tested for crosslinking reaction with azido-PEG (MW $10000 \mathrm{Da}$ ) in the presence of $\mathrm{CuSO}_{4}$, THPTA ligand, and sodium ascorbate reducing agent (Scheme 1), forming a strong hydrogel within $30 \mathrm{~s}$ (results shown for 3, Fig. 5). Hydrogels formed at a final weight percent of $7.5 \mathrm{wt} \%$ with stoichiometric ruthenium crosslinker, generating elasticity nearing $1 \mathrm{kPa}$ (Fig. 5). As expected, when exposed to visible light (400-500 $\mathrm{nm})$ the hydrogel rapidly lost its elastic properties, becoming a viscous liquid within 5 min (Fig. 5).

Next, a striped hydrogel was formed for multiplexing experiment via "layer-by-layer" reaction of azido-PEG with crosslinker

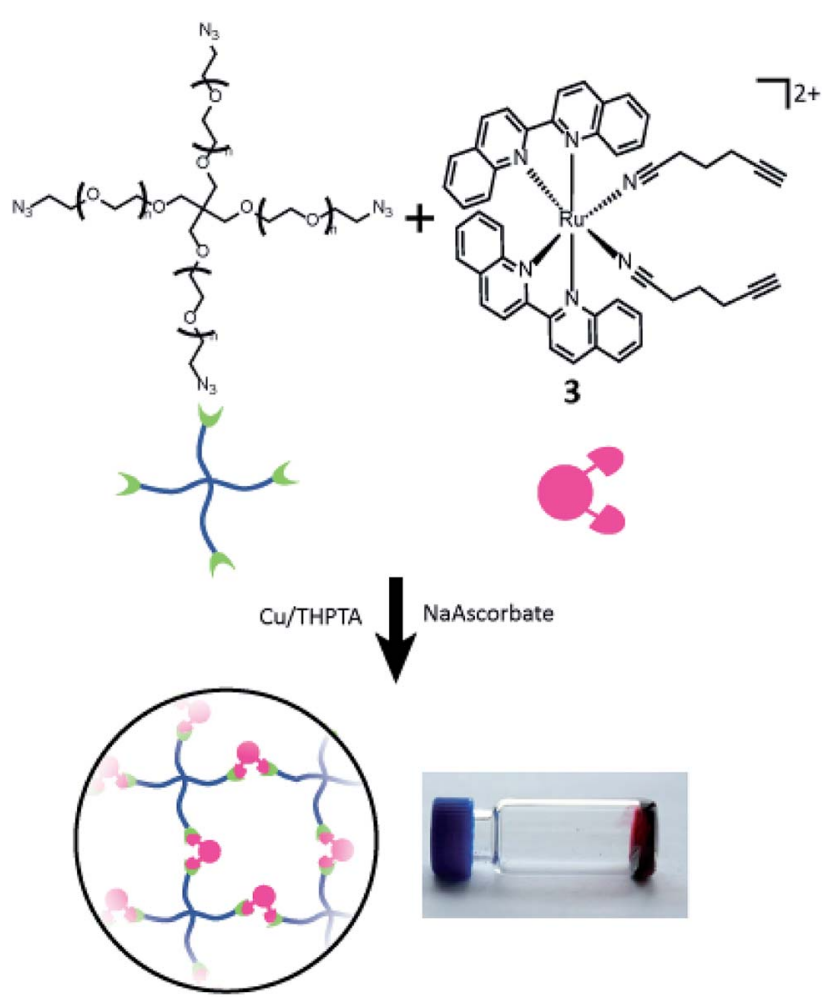

Scheme 1 Gelation of branched PEG via crosslinking reaction with 3.

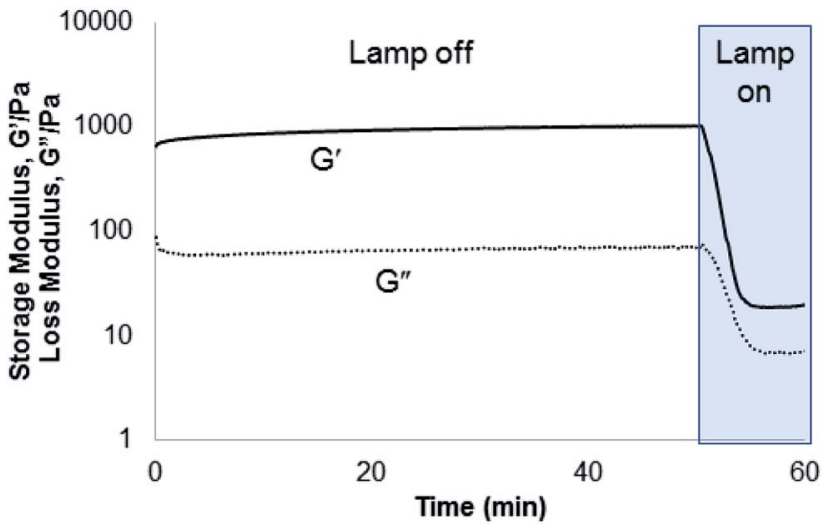

Fig. 5 Rheometry demonstrating gelation formed from the incorporation of 3 into a PEG hydrogel. The hydrogel was rapidly degraded under irradiation with $400-500 \mathrm{~nm}$ light $\left(25 \mathrm{~mW} \mathrm{~cm}^{-2}\right)$.

1, alternating with crosslinker 3 (Fig. 6). Orange light (592 nm) was used to degrade 3 selectively while leaving $\mathbf{1}$ intact, as demonstrated both in a solution experiment with equal parts 1 and 3 (Fig. 6A) and in the gel (Fig. 6B). A significant increase in absorbance at $590 \mathrm{~nm}$ confirmed the formation of the bisaquated product $\mathrm{Ru}(\mathrm{biq})_{2}\left(\mathrm{H}_{2} \mathrm{O}\right)_{2}, 3^{\prime \prime}$ (Fig. 6A). Finally, irradiation at $410 \mathrm{~nm}$ led to a significant decrease in absorbance at $423 \mathrm{~nm}$ and small increase at $590 \mathrm{~nm}$ due to formation of $\mathrm{Ru}(\mathrm{bpy})_{2}(-$ $\left.\mathrm{H}_{2} \mathrm{O}\right)_{2}, \mathbf{1}^{\prime \prime}$ (Fig. 6A, S1 $\dagger$ ), and rapidly degraded the remaining hydrogel sections crosslinked by $\mathbf{1}$ (Fig. 6B). The sequence of irradiation is important in this case, as compound $\mathbf{3}$ absorbs

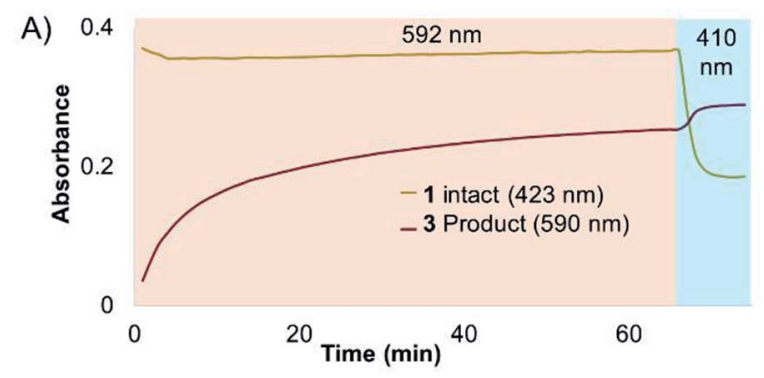

B)

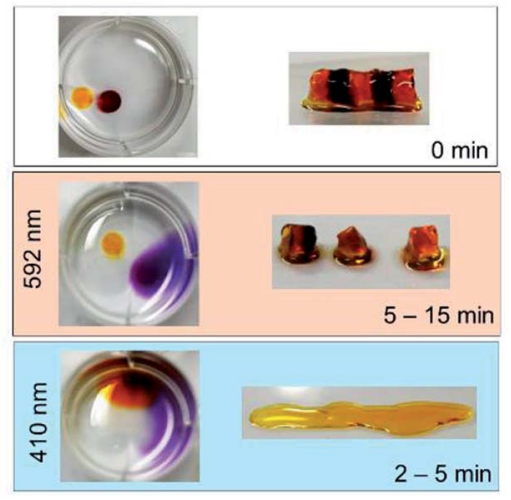

Fig. 6 Selective degradation of 1 and 3 in solution and hydrogel. (A) Irradiation at $592 \mathrm{~nm}$ photolyzed 3 in solution while leaving 1 intact, until irradiation at $410 \mathrm{~nm}$. (B) Striped hydrogel incorporating alternating sections of 1 and 3 was selectively degraded at $592 \mathrm{~nm}$, leaving the orange gel regions intact. The remaining sections crosslinked by 1 were degraded by $410 \mathrm{~nm}$ light. 
both 410 and $592 \mathrm{~nm}$ light and will be degraded by both wavelengths.

We developed spectrally tuneable ruthenium polypyridyl crosslinkers with two pendant alkynes for hydrogel formation, and high photolysis efficiency for multiplexed, visible-light gel degradation. Replacing bipyridine with more pi-conjugated biquinoline ligands red-shifted the absorbance, generating a series of sequentially red-shifted compounds. Incorporation of two flexible 5-hexynenitrile ligands at the $\mathrm{Ru}^{2+}$ center enabled CuAAC crosslinking reactions, while also facilitating subsequent photodegradation of gels incorporating these Ru crosslinkers. This represents the first example to our knowledge of a two-color hydrogel system that can be selectively activated by two different visible wavelengths. Such Ru crosslinkers may be applied broadly in materials chemistry, or alternately employed for generating photoactive versions of circular oligos, ${ }^{21}$ peptides, or other bis-azide containing molecules.

\section{Conflicts of interest}

There are no conflicts to declare.

\section{Acknowledgements}

Many thanks to Jonathan Gallarga for his assistance with the rheometry experiments, and Pat Carroll for his work in solving the crystal structures. The authors gratefully acknowledge financial support from the NIH (R01 GM-083030), the NSF through the University of Pennsylvania, Materials Research Science and Engineering Center (MRSEC, DMR-1720530), and the UPenn Chemistry Department.

\section{References}

1 N. A. Smith, P. Zhang, S. E. Greenough, M. D. Horbury, G. J. Clarkson, D. McFeely, A. Habtemariam, L. Salassa, V. G. Stavros, C. G. Dowson, et al., Chem. Sci., 2017, 8, 395404.

2 A. Li, C. Turro and J. J. Kodanko, Chem. Commun., 2018, 54, 1280-1290.

3 F. Reeßing and W. Szymanski, Curr. Med. Chem., 2018, 24, 4905-4950.

4 A. Döbber, A. F. Phoa, R. H. Abbassi, B. W. Stringer, B. W. Day, T. G. Johns, M. Abadleh, C. Peifer and L. Munoz, ACS Med. Chem. Lett., 2017, 8, 395-400.

5 M. M. Dcona, D. Mitra, R. W. Goehe, D. A. Gewirtz, D. A. Lebman and M. C. T. Hartman, Chem. Commun., 2012, 48, 4755.

6 S. Ki Choi, T. Thomas, M.-H. Li, A. Kotlyar, A. Desai and J. R. Baker Jr, Chem. Commun., 2010, 46, 2632.

7 A. M. Kloxin, A. M. Kasko, C. N. Salinas and K. S. Anseth, Science, 2009, 324, 59-63.

8 A. Ovsianikov, A. Deiwick, S. Van Vlierberghe, P. Dubruel, L. Möller, G. Dräger and B. Chichkov, Biomacromolecules, 2011, 12, 851-858.
9 D.-S. Shin, J. You, A. Rahimian, T. Vu, C. Siltanen, A. Ehsanipour, G. Stybayeva, J. Sutcliffe and A. Revzin, Angew. Chem., Int. Ed., 2014, 53, 8221-8224.

10 K. Peng, I. Tomatsu, B. van den Broek, C. Cui, A. V. Korobko, J. van Noort, A. H. Meijer, H. P. Spaink and A. Kros, Soft Matter, 2011, 7, 4881.

11 C. M. Kirschner, D. L. Alge, S. T. Gould and K. S. Anseth, Adv. Healthcare Mater., 2014, 3, 649-657.

12 C. K. Arakawa, B. A. Badeau, Y. Zheng and C. A. DeForest, Adv. Mater., 2017, 29, 1703156.

13 D. R. Griffin and A. M. Kasko, J. Am. Chem. Soc., 2012, 134, 13103-13107.

14 A. M. Rosales, K. M. Mabry, E. M. Nehls and K. S. Anseth, Biomacromolecules, 2015, 16, 798-806.

15 T. E. Brown, I. A. Marozas and K. S. Anseth, Adv. Mater., 2017, 29, 1605001.

16 L. Wu, Y. Wang, J. Wu, C. Lv, J. Wang and X. Tang, Nucleic Acids Res., 2013, 41, 677-686.

17 L. Kröck and A. Heckel, Angew. Chem., Int. Ed., 2005, 44, 471473.

18 D. D. Young, M. O. Lively and A. Deiters, J. Am. Chem. Soc., 2010, 132, 6183-6193.

19 S. Yamazoe, Q. Liu, L. E. McQuade, A. Deiters and J. K. Chen, Angew. Chem., Int. Ed., 2014, 53, 10114-10118.

20 S. Yamazoe, I. A. Shestopalov, E. Provost, S. D. Leach and J. K. Chen, Angew. Chem., Int. Ed., 2012, 51, 6908-6911.

21 J. C. Griepenburg, T. L. Rapp, P. J. Carroll, J. Eberwine and I. J. Dmochowski, Chem. Sci., 2015, 6, 2342-2346.

22 J. C. Griepenburg, B. K. Ruble and I. J. Dmochowski, Bioorg. Med. Chem., 2013, 21, 6198-6204.

23 B. N. Goguen, B. D. Hoffman, J. R. Sellers, M. A. Schwartz and B. Imperiali, Angew. Chem., Int. Ed., 2011, 123, 57855788.

24 C. W. Riggsbee and A. Deiters, Trends Biotechnol., 2010, 28, 468-475.

25 N. Ankenbruck, T. Courtney, Y. Naro and A. Deiters, Angew. Chem., Int. Ed., 2018, 57, 2768-2798.

26 J. Hemphill, E. K. Borchardt, K. Brown, A. Asokan and A. Deiters, J. Am. Chem. Soc., 2015, 137, 5642-5645.

27 S. Mura, J. Nicolas and P. Couvreur, Nat. Mater., 2013, 12, 991-1003.

28 M. Huisman, J. K. White, V. G. Lewalski, I. Podgorski, C. Turro and J. J. Kodanko, Chem. Commun., 2016, 52, 12590-12593.

29 T. L. Rapp, C. B. Highley, B. C. Manor, J. A. Burdick and I. J. Dmochowski, Chem.-Eur. J., 2018, 24, 2328-2333.

30 M. A. Azagarsamy and K. S. Anseth, Angew. Chem., Int. Ed., 2013, 52, 13803-13807.

31 D. Y. Wong, D. R. Griffin, J. Reed and A. M. Kasko, Macromolecules, 2010, 43, 2824-2831.

32 J. W. Walker, J. A. Mccray and G. P. Hess, Biochemistry, 1986, 25, 1799-1805.

33 M. A. Azagarsamy, D. D. McKinnon, D. L. Alge and K. S. Anseth, ACS Macro Lett., 2014, 3, 515-519.

34 I. Aujard, C. Benbrahim, M. Gouget, O. Ruel, J.-B. Baudin, P. Neveu and L. Jullien, Chem.-Eur. J., 2006, 12, 6865-6879. 
35 R. G. Wylie and M. S. Shoichet, J. Mater. Chem., 2008, 18, 2716.

36 B. Yan, J.-C. Boyer, N. R. Branda and Y. Zhao, J. Am. Chem. Soc., 2011, 133, 19714-19717.

37 X. Zeng, X. Zhou and S. Wu, Macromol. Rapid Commun., 2018, 1800034.

38 B. Yan, J.-C. Boyer, D. Habault, N. R. Branda and Y. Zhao, J. Am. Chem. Soc., 2012, 134, 16558-16561.

39 D. Wang, M. Wagner, H.-J. Butt and S. Wu, Soft Matter, 2015, 11, 7656-7662.

40 Z. Leonardo, C. Cecilia, A. Pablo, L. Baraldo and R. Etchenique, J. Am. Chem. Soc., 2003, 125, 882-883.

41 M. Huisman, J. K. White, V. G. Lewalski, I. Podgorski, C. Turro and J. J. Kodanko, Chem. Commun., 2016, 52, 12590-12593.

42 L. N. Lameijer, D. Ernst, S. L. Hopkins, M. S. Meijer, S. H. C. Askes, S. E. LeDévédec and S. Bonnet, Angew. Chem., Int. Ed., 2017, 56, 11549-11553.

43 R. N. Garner, L. E. Joyce and C. Turro, Inorg. Chem., 2011, 50, 4384-4391.

44 R. Sharma, J. D. Knoll, P. D. Martin, I. Podgorski, C. Turro and J. J. Kodanko, Inorg. Chem., 2014, 53, 3272-3274.

45 T. Respondek, R. Sharma, M. K. Herroon, R. N. Garner, J. D. Knoll, E. Cueny, C. Turro, I. Podgorski and J. J. Kodanko, ChemMedChem, 2014, 9, 1306-1315.

46 B. A. Albani, C. B. Durr and C. Turro, J. Phys. Chem. A, 2013, 117, 13885-13892.

47 J. D. Knoll, B. A. Albani, C. B. Durr and C. Turro, J. Phys. Chem. A, 2014, 118, 10603-10610.

48 X. Zeng, X. Zhou and S. Wu, Macromol. Rapid Commun., 2018, 1800034.
49 C. Xie, W. Sun, H. Lu, A. Kretzschmann, J. Liu, M. Wagner, H.-J. Butt, X. Deng and S. Wu, Nat. Commun., 2018, 9, 3842. 50 V. V. Rostovtsev, L. G. Green, V. V. Fokin and K. B. Sharpless, Angew. Chem., Int. Ed., 2002, 41, 2596-2599.

51 C. Tornoe, C. Christensen and M. Meldal, J. Org. Chem., 2002, 67, 3057-3064.

52 L. N. Lameijer, D. Ernst, S. L. Hopkins, M. S. Meijer, S. H. C. Askes, S. E. LeDévédec and S. Bonnet, Angew. Chem., Int. Ed., 2017, 56, 11549-11553.

53 L. M. Loftus, A. Li, K. L. Fillman, P. D. Martin, J. J. Kodanko and C. Turro, J. Am. Chem. Soc., 2017, 139, 18295-18306.

54 P. P. Goswami, A. Syed, C. L. Beck, T. R. Albright, K. M. Mahoney, R. Unash, E. A. Smith and A. H. Winter, J. Am. Chem. Soc., 2015, 137, 3783-3786.

55 N. Umeda, H. Takahashi, M. Kamiya, T. Ueno, T. Komatsu, T. Terai, K. Hanaoka, T. Nagano and Y. Urano, ACS Chem. Biol., 2014, 9, 2242-2246.

56 V. Crescenzi, L. Cornelio, C. Di Meo, S. Nardecchia and R. Lamanna, Biomacromolecules, 2007, 8, 1844-1850.

57 X. Hu, D. Li, F. Zhou and C. Gao, Acta Biomater., 2011, 7, 1618-1626.

58 S. Q. Liu, P. L. Rachel Ee, C. Y. Ke, J. L. Hedrick and Y. Y. Yang, Biomaterials, 2009, 30, 1453-1461.

59 D. A. Heller, Y. Levi, J. M. Pelet, J. C. Doloff, J. Wallas, G. W. Pratt, S. Jiang, G. Sahay, A. Schroeder, J. E. Schroeder, et al., Adv. Mater., 2013, 25, 1449-1454.

60 D. A. Ossipov and J. Hilborn, Macromolecules, 2006, 39, 1709-1718.

61 Y. Jiang, J. Chen, C. Deng, E. J. Suuronen and Z. Zhong, Biomaterials, 2014, 35, 4969-4985.

62 B. J. Adzima, Y. Tao, C. J. Kloxin, C. A. DeForest, K. S. Anseth and C. N. Bowman, Nat. Chem., 2011, 3, 256-259. 